\title{
EVALUATION OF MOTOR OIL CHARACTERISTICS AND DEGRADATION FACTORS FOR POSSIBILITIES OF CONTINUOUS DIAGNOSTICS
}

\author{
Slavomír KARDOŠ, Alena PIETRIKOVÁ \\ Department of Technologies in Electronics, Faculty of Electrical Engineering and Informatics, \\ Technical University of Košice, Letná 9, 04200 Košice, Slovak Republic, Tel.: +421 55602 3211, E-mail: slavomir.kardos@tuke.sk
}

\begin{abstract}
An increasing interest for monitoring of motor oils condition is devoted by automotive producers and researchers. Many studies are concerned to problematics of degradation factors and diagnostics. There is an increasing variety of sensors and systems for realtime monitoring of material characteristics. Utilization of such sensors is efficient for monitoring of motor oil aging. Using experimental samples a specific behaviour of motor oil was evaluated by study of degradation processes throughout the life cycle of engine oil. The key parameters - kinematic viscosity, dielectric constant and specific conductivity were examined for better understanding of ongoing degradation processes that take place in engine motor oil. These characteristics are discussed and they are the background for continuous diagnostics.
\end{abstract}

Keywords: motor oil, degradation factors, sensor, diagnostics, viscosity, conductivity, density

\section{INTRODUCTION}

An automobile engine consists of a large number of moving parts and its reliability is directly joined with lubrication ability of motor oil. Recently there are more than 1.2 milliards of registered automobiles and annual sale exceeds 84 million new automobiles.

Continuous diagnostics of motor oil has increasing attention by automobile developers with accent at effectiveness of media usage and ecologic factors, which are joined with correct automobile engine operation as well as with operation and service charges. [2][3]

Motor oil is produced by refining and by modification of certain hydrocarbon classes which are contained in petroleum as well as it contains synthetically produced components. It is non-polar chemical substance, what in certain temperature range has nature of dense and viscous liquid. Variable orderliness and complexity of hydrocarbon molecules based on atoms of carbon, hydrogen and small ratio of oxygen determine the physical and chemical properties of the oil.

Motor oil is a complex compound, which can be characterized by two main components: base oil and additives. The base oil represents petroleum or synthetic base or their combination. The additives provide prevention of base oil against deterioration and corrosion, neutralize acidic components, keep viscosity stability and have dispersion and detergent effect. These additives facilitate to satisfy high requirements of engine operation at extreme conditions. [3][5][6]

Main processes of motor oil degradation are oxidation, chemical changes caused by thermal processes, corrosion, mechanical decomposition and contamination.

Motor oil diagnostics in real time introduces a challenge for modern sensor systems, because only small variation of elementary parameter can give rise the rapid change of significant property. Therefore it is important to state the correlation between elementary parameters and properties of motor oil.

More exact data about motor oil quality lead to more correct determination of oil change interval. They also allow a better view to its actual state as well as about automobile engine condition itself. As a result, it can lead to cost saving due to effectiveness and operation fault prediction. [3]

Recent motor oil diagnostics has two principally different approaches - direct and indirect. Indirect diagnostics do not dispose with system of motor oil parameters diagnostics, but with system of motor operation parameters measurement and evaluation. Such parameters are continually acquired during the motor operation cycle and by utilization of appropriate algorithm the motor oil condition is estimated. The infirmity of motor oil parameters utilization for motor oil diagnostics thus rests in the reality, that such parameters do not monitors the oil parameters, so the critical problems as the contamination by fuel can be omitted. Some systems as General Motors Oil-Life system and Daimler Chrysler Assyst are such based systems.

Automobile producers endeavour to quantify the motor oil quality by direct measurement of parameters in real time by utilization of on-board sensing system based mainly on:

- evaluation of parameters using on-board sensing of temperature, viscosity, density, and dielectric properties,

- determination of correlation between level of contamination and oil properties change,

- quantification of oil properties change with motor operation cycle,

- identification of possible reasons of changes in motor oil properties.

\section{MEDIA CHARACTERISTICS}

In gasoline engines, the motor oil is exposed to temperatures around $160^{\circ} \mathrm{C}$ and in engines powered by diesel fuel to temperatures above the $315^{\circ} \mathrm{C}$. Oil layer covering metal parts prevents the oxygen to oxidize at increased operating temperatures, what prevents to corrosion. This function supports the corrosion inhibitors. Motor oil also absorbs the smuts generated by fuel combustion process. 
Existence of relevant parameters as attributes of properties is the assumption for diagnostics of motor oil condition. Among wide range of affected parameters they are mainly the dielectric properties, electrical conductivity, viscosity and $\mathrm{pH}$.

Understanding of outer and inner influences at ability of motor oil lubrication leads to study these factors from the view of their impact to significant material characteristics. [3]

\subsection{Rheological properties}

They are represented mainly by viscosity - measure of resistance or inner friction against deformation or flow of liquid media, which is deformed by shear or tensile stress. The Newton law was formulated for laminar flow, by which the tangential stress is proportional to dynamic viscosity and to velocity gradient of liquid.

At Newtonian liquids there is a force needed for sustaining a constant velocity of moving object with given contact area in the face with the reference surface [7][8]

$F=\tau S=\eta \frac{v}{h} S[N]$

wherein shear stress

$\tau=\eta \frac{d v}{d y}=\eta j\left[N / m^{2}\right]$

where $\eta$ is the dynamic viscosity [Pa.s] and $j=\frac{d v}{d y}$ is velocity gradient $\left[\mathrm{s}^{-1}\right]$.

From practical view the kinematic viscosity was introduced:

$v=\frac{\eta}{\rho}\left[m^{2} / s\right]$

where $\rho\left[\mathrm{kg} / \mathrm{m}^{3}\right]$ is the density of the liquid. [7][11]

In motor aggregate environment, the temperature dependence of viscosity is the key property and close corresponds to Arrhenius-type equation:

$\mu=\mu_{0} e^{E_{\mu} / R T}[$ Pa.s $]$

where $\mu_{0}$ is viscosity at reference temperature and $E_{\mu}$ is temperature coefficient for viscosity.

Viscosity of the liquid decreases with temperature and at lubrication media has a strong hyperbolic dependency. [9][12]

\subsection{Media density}

The density is given by mass of substance which belongs to a volume unit, i.e. $\rho=m / V\left[\mathrm{~kg} / \mathrm{m}^{3}\right]$ and it is related to atomic mass and molecular bonds. It is influenced by temperature, pressure and surface tension. For practical purposes the relative density was introduced, what is usually related to water. [1][3]

\section{3. $\mathrm{pH}$ or TAN/TBM}

Corrosion by influence of acidic components is caused by acting of hydrogen ions $\left(\mathrm{H}^{+}\right)$, so that measurement of its concentration can provide a good view to corrosive processes acting in motor oil.

Additive components sustain the $\mathrm{pH}$ in equilibrium and no acidic molecules should be present in oil. [10][13] The $\mathrm{pH}$ is the measure of hydrogen ions concentration in logarithmic representation:

$p H=-\log \left[H^{+}\right]$

its value in unused motor oil is in range of 7-8 and it is still decreasing. TBN/TAN parameters were introduced specially for motor oil quality determination and they are defined through neutralization of acidity or basicity. $[3][13][19]$

\subsection{Specific conductivity}

Specific conductivity is the ability to conduct the electric current by

$\gamma=\frac{l G}{S}=\left[\frac{m S}{m^{2}}\right]$

where $G$ is electric conductivity of conductor with length of $l$ and cross-section of $S$.

Electric conductivity of motor oil is strongly related to presence of water and microscopic metallic parts. Increasing temperature supports dissociation of ions, growing its mobility and resulting increasing conductivity of the media. They represent dissociated positive and negative ions. Electric conductivity varies also by measure of additives declination. [5][10]

Measurement of motor oil conductivity needs equipment for very low current sensing due to conductivity of media in the order of $\mathrm{pS} / \mathrm{m}$. [10][14]

\subsection{Dielectric properties}

Dielectric properties reflect the measure of interaction of oscillating electric field in molecules. Dielectric constant can be derived from Debye's equation for molar polarization:

$\frac{\varepsilon_{r}-1}{\varepsilon_{r}+2}=\frac{\alpha+\mu^{2} / 3 k T}{L \rho 3 M_{H}}$

where $\varepsilon_{r}$ is dielectric constant of the media, $\alpha$ its polarizability, $\mu$ is dipole moment, $\mathrm{k}$ is the Boltzmann constant $\left(1.33 \times 10^{-23} \mathrm{~J} / \mathrm{K}\right), \quad T$ is thermodynamic temperature, $\mathrm{L}$ is the Avogadro's constant (6.02214129 $\times$ $\left.10^{23} \mathrm{~mol}^{-1}\right), \rho$ is oil density and $M_{H}$ is molecular weight of the oil.

During normal operation cycle the motor oil temperature is close to $100^{\circ} \mathrm{C}$. Dielectric constant of motor oils is in the range from 2.1 to 2.8 and increases approximately $0.0013-0.05 \% /{ }^{\circ} \mathrm{C}$. Debye's equation indicates that dipole moment has indirect proportion with temperature. 
Dielectric properties of produced motor oils are markedly dependent by content of paraffines and naphthalens and during operation by water and other impurities content.

Dielectric constant is a fundamental property, which express the measure of material polarization. It is dimensionless value, given by permittivity relative to vacuum by $\varepsilon_{r}=\varepsilon / \varepsilon_{0}$. [21][22]

\section{SAE AND ASTM STANDARD}

Motor oil classification is specified by Society of Automotive Engineers (SAE) by numerical labeling according to viscous properties at low and high operation temperatures. Modern multigrade motor oils are defined by SAE J300 as a combination of winter and summer class.

Kinematic viscosity and density of motor oil are temperature dependent characteristics and they are defined by SAE viscosity classes. Density has character of decreasing linear dependence with temperature (Fig. 1). Motor oil producers declare reference value of density at $15^{\circ} \mathrm{C}$ in $\mathrm{kg} / \mathrm{l}$ or $\mathrm{g} / \mathrm{cm}^{3}$. Kinematic viscosity is given by ASTM D445 standard at temperatures of 40 and $100^{\circ} \mathrm{C}$ in $\mathrm{mm}^{2} / \mathrm{s}$ or $\mathrm{cSt}$.

\section{EVALUATION OF SAE STANDARDIZED MULTIGRADE OILS CHARACTERISTICS}

Respecting SAE standard the dependencies of density and kinematic viscosity (using Anton Paar GmbH SVM3000 Stabinger Viscometer (ASTM D7042)) of most used multi-class motor oils were compiled in temperature range of $0-100^{\circ} \mathrm{C}$. [15][20][24]

Density of evaluated oils follow close linear dependences, therefore the slope of density of SAE standardized motor oils can be derived using reference values. [23]

Kinematic viscosity of motor oil represents decreasing hyperbolic dependence (Fig. 2). Under temperatures of $0^{\circ} \mathrm{C}$ the dependence markedly changes with temperature. In contrast, above temperature of $50^{\circ} \mathrm{C}$ the kinematic viscosity of all motor oil classes tend to $10 \mathrm{~mm}^{2} / \mathrm{s}$. Motor oil producers state the values of kinematic viscosity at 40 and $100^{\circ} \mathrm{C}$.

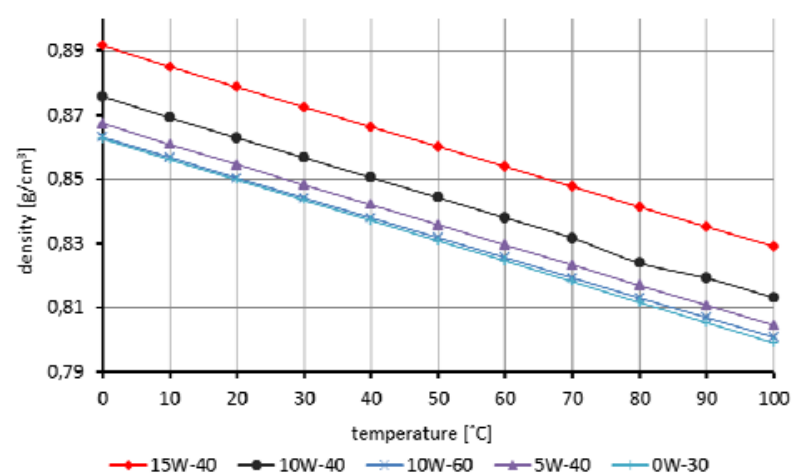

Fig. 1 Temperature dependences of density of frequently used SAE-standard multi-class motor oils
Motor oil viscosity influences the process of correct lubricating during automobile engine operation. During winter season influences start ability of engine and during summer season must provide sufficient separation of moving parts. Viscosity measurement provides view to continuing degradation processes and requires convenient attention. [3][16]

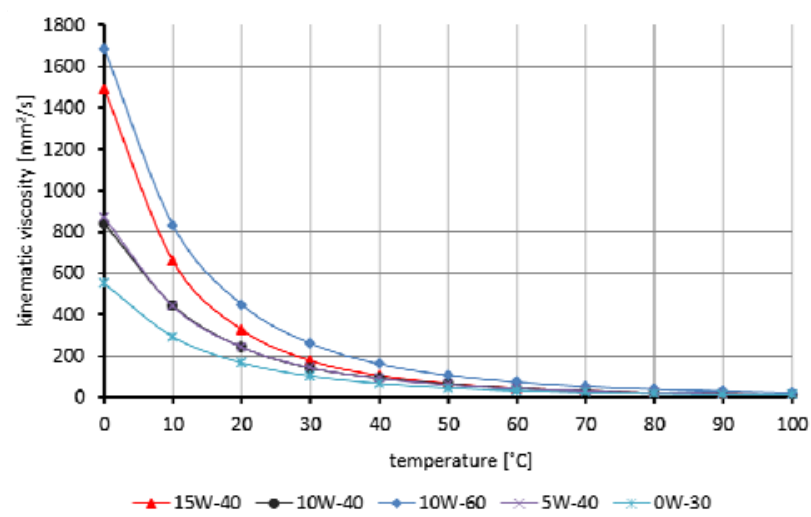

Fig. 2 Temperature dependences of kinematic viscosity according to SAE (D7042)

\section{EXPERIMENTAL SAMPLES}

Measurements of relevant characteristics were realized at samples of commercially used multi-grade motor oil Shell Helix 5W-30. They were acquired during 12-month operation interval with 11,756 of ride kilometers at Kia C'eed automobile with 1.41 petrol engine. Average ride cycle was 30 kilometers with extramural operation prevailing.

Dynamic viscosity of samples was measured in temperature range of $5-85^{\circ} \mathrm{C}$ by Anton Paar MCR (Modular Compact Rheometer) 502 with vibration or rotation mode ability. [25]

Indirect evaluation of specific conductivity was realized by measurement of ac voltage $u_{S}$ at measurement resistor $\mathrm{R}_{\mathrm{S}}$ with $100 \mathrm{k} \Omega$ value using measurement cell, calibrated at $\mathrm{KCl}$ solution with known specific conductivity. The specific conductivity of oil media was evaluated through calculated $\mathrm{k}$ constant of measurement cell by

$$
\gamma=\frac{G_{k}}{k}=\frac{1}{R_{k} k}=\frac{1}{R_{s}\left(\frac{u}{u_{S}}-1\right) k}[S / m]
$$

The samples were measured in temperature range of 0 $100^{\circ} \mathrm{C}$ by Agilent $34411 \mathrm{~A}$ digital multimeter. Measurement circuit was driven by $1 \mathrm{kHz}$ sine signal with amplitude of $10 \mathrm{~V}$ (peak-to-peak) by Rigol DG5071 signal generator.

Dielectric constant is important indicator of motor oil quality. Its indirect measurement is based on capacity measurement using sensed media as the dielectrics. Changes in motor oil dielectric constant can indice the presence of contamination, e.g. water, fuel, impurities, etc. as well as changes in motor oil composition due to oxidation and deficiency of additives. [21][22] 


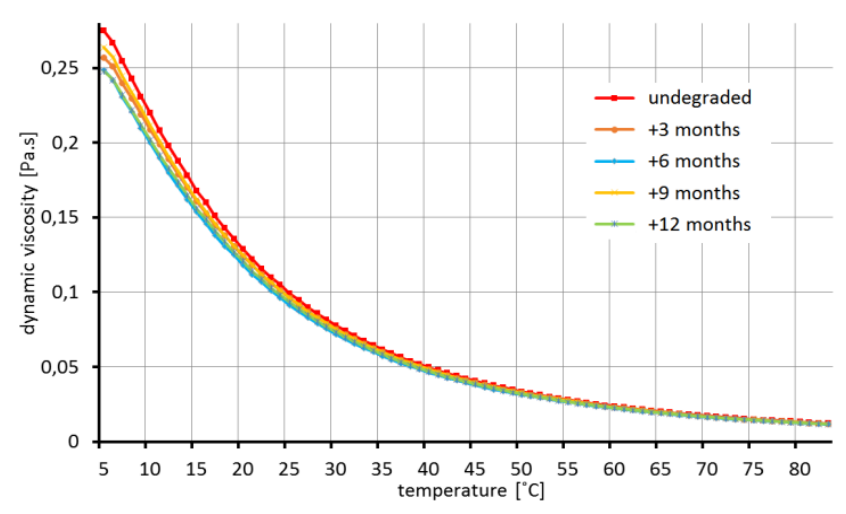

Fig. 3 Temperature dependences of kinematic viscosity of samples

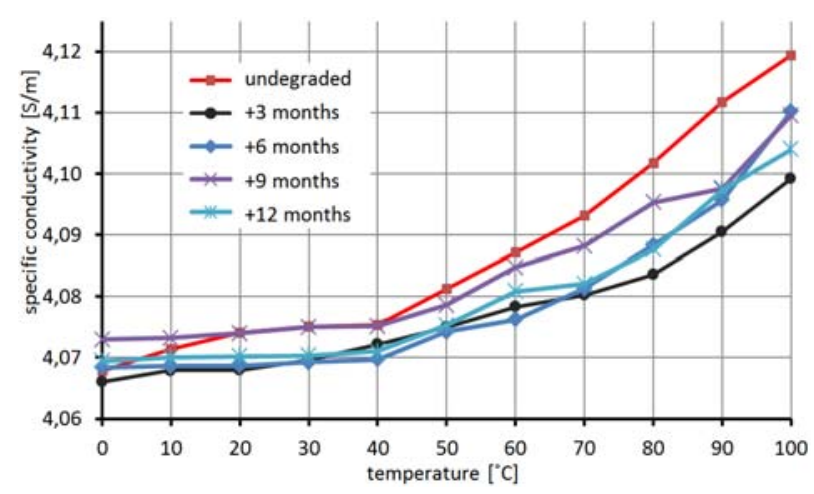

Fig. 4 Temperature dependences of specific conductivity of samples at $1 \mathrm{kHz}, 10 \mathrm{~V}$ (peak-to-peak)

For measurement purposes the cylindrical capacitor was constructed and utilized. Using RLC200 (Programmable Automatic RLC Meter), through temperature range of $0-100^{\circ} \mathrm{C}$, the capacity $C_{x}$ of measurement capacitor was related to its value $C_{0}$ in room conditions atmosphere by $\varepsilon_{r}=C_{x} / C_{0}$.

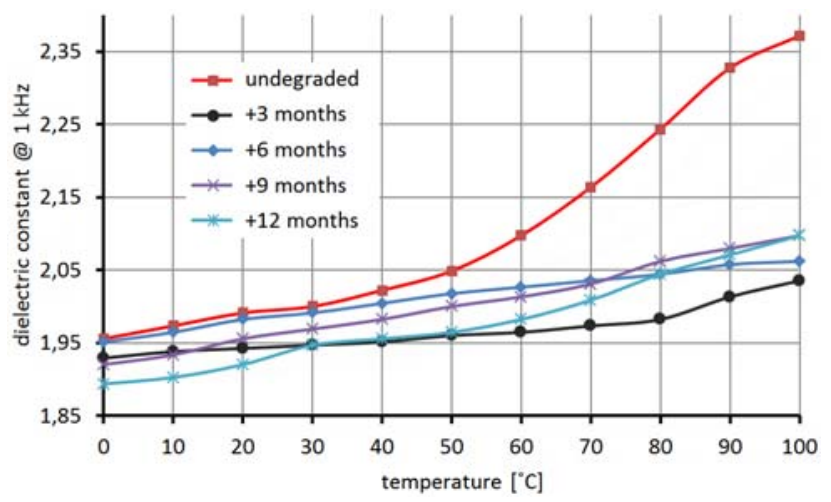

Fig. 5 Temperature dependences of dielectric constant of samples at $1 \mathrm{kHz}$

\section{DISCUSSION}

Graphical representation analysis (Fig. 3) points to decreasing trend of viscosity through operation cycles. It is due to composition character connected mainly with decomposition of molecular chains by thermal influence and contamination by fuel and water. At the base of viscosity change measure it is possible to identify, which factor has more meaning occurrence. More precise identification is possible by other parameters evaluation, e.g. conductivity and dielectric parameters, due to complex character of physical changes.

The conductivity characteristics (Fig. 4) are relative to influence of impurities concentration, which have various origins. Their concentration grows with detrition of metallic surfaces and absorption of water, fuel and combustion products. These components compose the electrolyte with motor oil. Conductivity temperature dependence of this substance is related with dissociation of such impurities and with mobility of ions variation. [28] Character of conductivity change is also associated with loss of additives concentration and with continuing oxidation. Depletion of additives introduces increased potential of acidic components formation, which affects all key characteristics. Moreover, variation of electric conductivity is liable to variation of water concentration, mainly in cold season operation. As a result, a systematic analysis is very complex problematics and therefore requires complex view to continuing degradation processes.

Typical lowering of dielectric constant with temperature is about $0.0013(0.05 \%)$ at $1{ }^{\circ} \mathrm{C}$, what is mainly related to slight specific density variation of motor oil. Dielectric constant of motor oil varies in 2.1-2.4 range (Fig. 5), what corresponds with presumptions. Expected growth of values through continuous degradation is relative to contaminants concentration growth, mainly water, microscopic metallic parts and various contaminants from combustion zone. Contamination by water introduce noticeable factor of dielectric constant variation due to strong polarity of water molecule. Values of dielectric constant at undegraded motor oil samples are connected with the highest concentration of additives.

\section{CONCLUSIONS}

Growing ecologic requirements at automotive industry segment influence the maintenance with working media. Motor oil diagnostics allows view at actual oil condition, which properties influence automobile operation on a large scale. Motor oil consists of complex composition of chemical substances, which are affected by various inner and outer factors. Monitoring of important parameters is a serious challenge for practical utilization of sensor networks. Automotive companies focus on this problematics and introduce new solutions including various direct and indirect evaluation methods using proper algorithms.

Analysis of motor oil samples provides a view to relevant characteristics in the scope of continuing degradation processes. Mainly, the viscosity is the most important parameter in evaluation of motor oil condition, but it cannot provide the information about degradation factors. Evaluation of dielectric properties together with electric conductivity focus on character of continuing processes, what support reliable motor oil diagnostics. 


\section{ACKNOWLEDGMENTS}

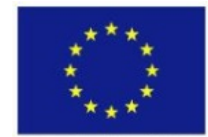

This paper was developed with support of the project „Vývoj unikátneho nízkoenergetického statického zdroja pre elektrosystémy“, ITMS 26220220029, that is co-financed from Structural Funds EU ERDF within Operational programme Research and Development V2008/2.2/01-SORO and preferred axis 2, Support of Research and Development.

Special thanks belong to MSc. Matej Fabian for active participation on the work and to doc. RNDr. Jana Tóthová, CSc. for help with viscosity measurements.

\section{REFERENCES}

[1] ELERT, G.: The Physics Hypertextbook, 2014, $<$ http://physics.info $>$

[2] International Energy Agency, 2016, $<$ https://www.iea.org $>$

[3] MANN, D.: Motor Oils and Engine Lubrication, 2008, <http://www.motor-oil-engineers.com/>

[4] THEODOROPOUlOS, T. E.: Oil, Gas and Petrochemicals, 2010, ISBN 978-99-9214-519-6.

[5] CLARK Ryan James, M. S.E.: On-Board Monitoring of Engine Oil, Western Michigan University, 2011, $<$ http://www.dtic.mil/cgibin/GetTRDoc?AD=ADA538688>

[6] VAFANEJAD, A.: MEMS in Automotive: Oil Quality Sensor, 2009, <http://repository.tudelft.nl/ view/ir/uuid\%3A1ed3ab0b-c131-45a1-8f85$26 \mathrm{ec} 8 \mathrm{f} 5 \mathrm{eb} 24 \mathrm{f} />$

[7] JANALÍK, J.: Viscosity of fluids and its measurement (in Czech), VŠB-TU Ostrava, 2010.

[8] TABOR, D.: Gases, Liquids and Solids and Other States of Matter, Cambridge Press, 1991, ISBN 97805-2140-667-3.

[9] FOWLER, M.: Viscosity, 2007, <http://galileo.phys. virginia.edu/classes/152.mfli.spring02/Viscosity.htm

[10] LINDNER, M.: Oil Condition Monitoring Using Electrical Conductivity, Machinery Lubrication, 6/2013, <http://www.machinerylubri cation.com/ $\operatorname{Read} / 29407 /$ oil-condition-monitoring $>$

[11] Kittiwake: Viscosity: A lubricant's most important characteristic, http://www.kittiwake.com/sites/ default/files/2\%20-\%20Viscosity\%20Dec12_0.pdf

[12] Neutrinum: Viscosity, 2012, <https://neutrium.net /fluid_flow/viscosity/>

[13] Col. auth.: All About Circuits, $\mathrm{pH}$ Measurement, 2016, http://www.allaboutcircuits.com/textbook/ direct-current/chpt-9/ph-measurement/
[14] Keithley, A Tektronix Company: Low Current Measurements, rev. 09.14.12, <http://www.tek.com /sites/tek.com/files/media/document/resources/LowC urtMsmntsAppNote.pdf $>$

[15] Noria Corporation: Oil Viscosity, Machinery Lubrication, $\quad 11 / 2002, \quad<$ http://www.machinery lubrication.com/Read/411/oil-viscosity>

[16] Dare Instruments: Viscosity Index and Oil Analysis, 2003, <http://www.dareinc.com/viscosityindex>

[17] Noria Corporation: Why an Oil's Viscosity Drops, Machinery Lubrication, http://www.machinery lubrication.com/Read/29144/oil-viscosity-drops

[18] WILLIAMSON, M.: Automotive Fluids, KEW Engineering, 2009, <http://www.kewengineering.co. uk/Auto_oils/oil_viscosity_explained.htm>

[19] KOHLMANN, F. J.: What is $\mathrm{pH}$, and how is it measured? Hach Company, 2003, <http://extension. psu.edu/food/entrepreneurs/equipment/what-is-phand-how-is-it-measured-1>

[20] D2270-04, 2004, Standard Practice for Calculating Viscosity Index from Kinematic Viscosity at 40 and $100^{\circ} \mathrm{C}$, ASTM International, West Conshohocken, PA， 2004， <http://www.astm.org/ DATABASE. CART/HISTORICAL/D2270-04.htm>

[21] CAREY, A.: The Dielectric Constant of Lubrication Oils, 1998, <http://www.dtic.mil/cgi-bin/GetTRDoc? $\mathrm{AD}=\mathrm{ADA} 347479>$

[22] CAREY A. - HAYZEN, A. J.: The Dielectric Constant and Oil Analysis, 2001, $<$ http://www.machinerylubrication.com/Read/226/di electric-constant-oil-analysis>

[23] Viscopedia, Anton Paar GmbH: <http://www.visco pedia.com/viscosity-tables/substances/engine-oil/>

[24] Anton Paar GmhH: SVM 3001 datasheet, Stabinger Viscometer

[25] Anton Paar GmbH: MCR502 datasheet, <http:// www.anton-paar.com/?eID=documents Download \&document $=18378 \& \mathrm{~L}=6>$

Received May 26, 2016, accepted July 6, 2016

\section{BIOGRAPHIES}

Slavomír Kardoš defended his PhD. thesis in the field of capacitive position sensors. His work is oriented to interconnection techniques, fine thick film technologies, passive components and MEMS technologies.

Alena Pietriková is a graduate of the Technical University in Košice in 1980 at the Department of Material science. She works as a Full Professor at the Department of Technologies in Electronics Faculty of Electrical Engineering and Informatics. Her research area is in the field of thick-film technologies, assembling technologies in electronics, materials for electronics. 